\section{Naked to the Bone}

\section{MEDICAL IMAGING IN THE TWENTIETH CENTURY}

\section{By Bettyann Holtzmann Kevles \\ Helix Books, Addison-Wesley, \$18, 378 pp. ISBN 0-201-32833-X, 1998}

\section{Reviewed by James H. Anderson Department of Radiology Johns Hopkins School of M edicine Baltimore, Maryland 21205, USA}

This book is part of the Sloan Technology Series (which receives support from the Alfred P. Sloan Foundation)-a series of informative books presenting to the general reader a description of critical twentieth century technologies in a manner that conveys both the technical and human dimensions of the subject. The goal of this series is to improve public understanding of modern technology, its origins and its impact on our lives.

Naked to the Bone is a very well written and researched volume that relates the fascinating history of medical imaging from its pre-twentieth-century roots beginning with Roentgen's discovery of X-rays to the relatively recent developments of, for example, magnetic resonance imaging (MRI) and positron emission tomography (PET).

$X$-rays have always been an enigma for the general public. This book makes a significant contribution to demystifying the science of Roentgenology and to relating the development of $\mathrm{X}$-rays to major changes in medical care and social reform that accompanied the turn of the century. The author's ability to interrelate the scientific and social impact of $X$-ray imaging is an important factor in capturing and maintaining the interest of the reader. Relating the use of $X$-rays to historical events and human experiences in the arts and humanities adds interest and perspective to the subject. This relationship is also emphasized in the appendix by means of a timeline chart. Few of us can forget the fascination we experienced the first time we saw an $\mathrm{X}$-ray revealing our hidden body parts. For many of us, this came through the 'shoe store fluoroscope'. It is with experiences such as these that the author guides us through the medical benefits as well as the health hazards of X-ray exposure.
Providing the reader with an understanding and appreciation of both the benefits and dangers of ionizing radiation is a clear message conveyed in this volume.

Although the book provides a good overview of the major clinical imaging technologies and applications, the subject of interventional radiology is not adequately addressed. This is unfortunate because many of the commonly used interventional image guided techniques such as angioplasty have replaced more invasive and expensive surgical procedures and have captured the attention and interest of the general public. The application of three-dimensional image reconstruction for pretreatment planning and its value in defining anatomic structure is al so not fully devel oped.

The section on PET is of particular interest and introduces the reader to the concept of imaging body chemistry and function. This modality is revolutionary because most medical imaging provides information about body structure or anatomy. More discussion of the use of nuclear magnetic resonance (NMR)

\section{ERRATUM}

Ribozyme rescue of photoreceptor cells in a transgenic rat model of autosomal dominant retinitis pigmentosa

Alfred S. LeWIN ${ }^{1,2}$, Kimberly A. Drenser ${ }^{1}$, Wiluam W. HausWirth ${ }^{1,2,3}$, Shimpel NishiKaWa ${ }^{4}$, Douglas

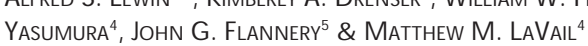

Nature Med. 4, 967-971, 1998

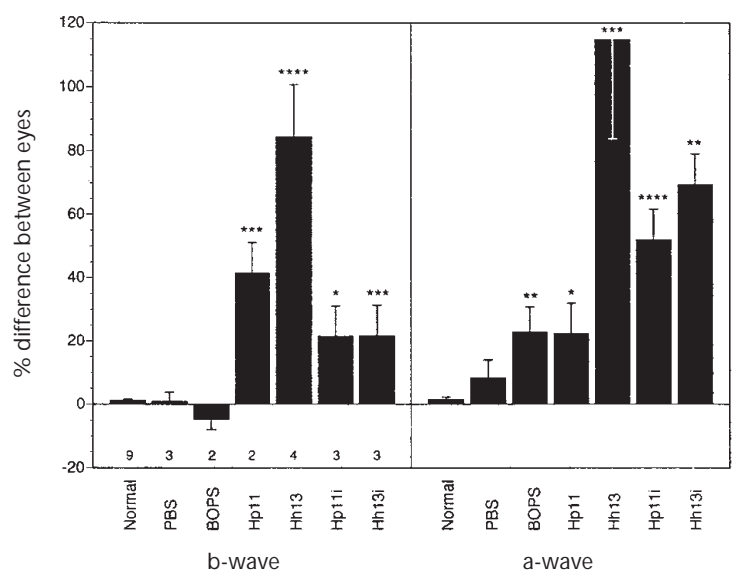

On page 970, Fig. 3b. The right panel should have been labeled "a-wave" instead of "b-wave". The correct Fig. $3 b$ is shown above. We regret this error. 